\title{
Isentropic Apparent Molal Compressibilities of Alcohols in Aqueous Solution. Relations to van der Waals Radii and the Scaled Particle Theory
}

\author{
HARALD HøILAND and EINAR VIKINGSTAD
}

Department of Chemistry, University of Bergen, N-5014 Bg-U, Norway

Isentropic apparent molal compressibilities of the homologous series of 1- and 2-propanol to 1- and 2-hexanol, the diols 1,2-propanediol, 1,2-2,3-, and 1,4-butanediol, 1,5-pentanediol, and 1,7-heptanediol in aqueous solution at 25 and $35^{\circ} \mathrm{C}$ have been determined from ultrasonic measurements. Values at infinite dilution have been evaluated. The additivity of isentropic group molal compressibilities have been investigated.

The isentropic molal compressibilities have been discussed in connection with partial molal volume data for the same alcohols. In relation to two solvation models, one based on the scaled particle theory, the other on van der Waals radii, the isentropic molal compressibilities were seen to be more sensitive to deficiencies in the models than the partial molal volumes.

In this paper we present experimental data for the isentropic apparent molal compres. sibilities of some alcohols and diols in aqueous solution. This thermodynamic quantity is of interest especially in connection with partial molal volume data. Non-thermodynamic solvation models may be constructed, and their usefulness can be checked against partial molal volume and compressibility data.

It has been demonstrated ${ }^{1,2}$ that the partial molal volumes of organic solutes in water may be calculated by adding the appropriate group partial molal volumes. The isentropic molal compressibility data available ${ }^{3,4}$ indicate additivity of group molal compressibilities as well. An advantage if such additivity relations can be established, is that different functional groups can be treated individually.
It has recently been shown that the partial molal volumes of organic solutes with more than three aliphatic carbon atoms per polar group can be calculated from eqn. (1). ${ }^{5}$

$\bar{V}^{0}=\frac{4}{8} \pi N\left(r_{\mathrm{w}}+\Delta\right)^{3}$

$r_{\mathrm{w}}$ is the van der Waals radius and $\Delta$ the thickness of an empty shell enclosing the solute. The value of $\Delta$ was on average found to be $0.53 \AA$.

The isentropic molal compressibility can in principle be calculated from eqn. (1):

$$
\left(\frac{\partial \bar{V}^{0}}{\partial P}\right)_{\mathrm{s}}=-\phi_{\mathbf{k}(\mathrm{s})}^{0}=4 \pi N\left(r_{\mathrm{w}}+\Delta\right)^{2}(\partial \Delta / \partial P)_{\mathrm{s}}
$$

The van der Wedls radius is here considered to be independent of pressure.

The partial molal volume can be represented as the sum:

$\bar{V}^{0}=\bar{V}_{\text {int }}+\Delta \bar{V}$

$\bar{V}_{\text {int }}$ is the intrinsic volume, the spherical cavity in which the solute is contained. This quantity can be calculated from the scaled particle theory. ${ }^{\circ}$

$\Delta \bar{V}$ is the volume change due to solutesolvent interactions. If $\bar{V}^{0}$ and $\bar{V}_{\text {int }}$ are known, $\Delta \bar{V}$ can be calculated from eqn. (3). This has been done for single ions. ${ }^{6}$ In this case $\Delta \bar{V}$ was seen to be negative and decreasing with increasing ionic radius.

Acta Chem. Scand. A 30 (1976) No. 9 


\section{EXPERIMENTAL}

The origin and purity of the alcohols have been described elsewhere. ${ }^{7}$

Isentropic coefficients of compressibility were determined by the "sing-around" principle. ${ }^{8}$ Ultrasonic pulses are passed through the solution and the frequencies of these pulses are measured, in this case by a Hewlett-Packard 5326A Time Counter averaging over periods of $10 \mathrm{~s}$. The isentropic coefficients of compressibility are then determined from eqn. (4).

$$
\beta_{\mathrm{s}}=10^{6} / u^{2} d
$$

$d$ is the density of the solution, $u$ the speed of sound [eqn. (5)].

$$
u=\frac{s}{1 / f-\tau}
$$

$s$ is the length of the cell, $f$ the measured fre. quencies, and $\tau$ the delay measured to $300 \mathrm{~ns}$. The cell was calibrated with water as the standard using the data of Del Grosso and Mader.' The isentropic apparent molal compressibilities were calculated from the equation:

$\phi_{\mathrm{k}(\mathrm{s})}=\frac{1000\left(\beta_{\mathrm{s}}-\beta_{\mathrm{so}}\right)}{\mathrm{md}_{\mathrm{o}}}+\beta_{\mathrm{s}} \phi_{\mathrm{v}}$

The subscript zero refers to pure water, $m$ is the molality, and $\phi_{\mathrm{v}}$ the apparent molal volume for which values are given.?

The cell was thermostated in a water bath The temperature fluctuations were less than $0.007{ }^{\circ} \mathrm{C}$.

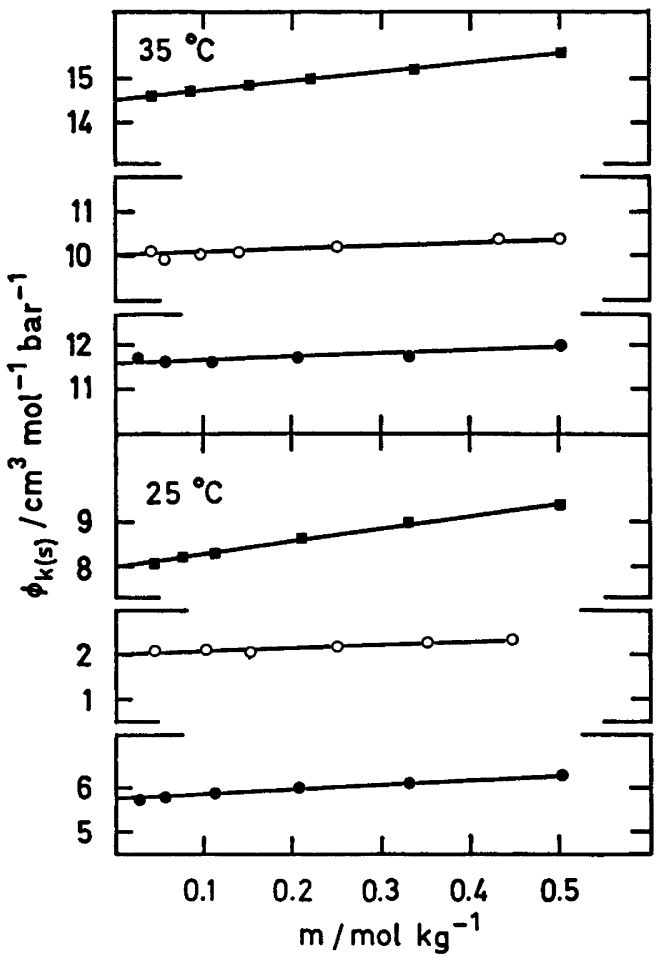

Fig. 1. Isentropic apparent molal compressibilities as functions of concentration. 1-propanol; O, 2-butanol; $\mathbf{a}, 1,5$-pentanediol.

Table 1. Isentropic molal compressibilities.

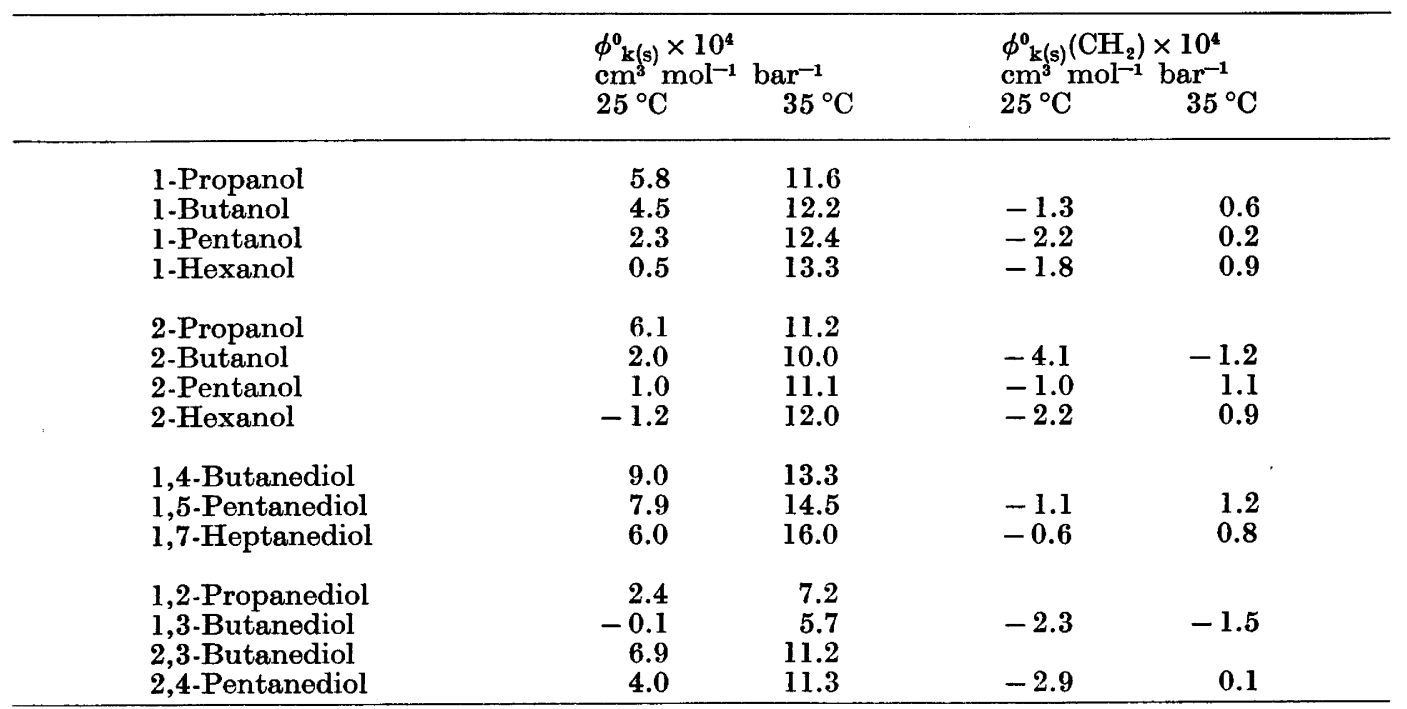

Acta Chem. Scand. A 30 (1976) No. 9 
The total error in the speed of sound measurements was estimated to $\pm 1 \mathrm{~cm} \mathrm{~s}^{-1}$.

\section{RESULTS}

The isentropic apparent molal compressibilities, $\phi_{\mathrm{k}, \mathrm{s}}$, were extrapolated to infinite dilution assuming a linear concentration depend. ence. Linear extrapolation function have generally been used for partial molal volumes of non-electrolytes, mainly based on empirical findings. Accepting such linearity, the isentropic apparent molal compressibilities should also be linear functions of concentration. Typical plots are shown in Fig. 1, oonfirming linearity. Results at infinite dilution are presented in Table 1. The error in $\phi_{k(\mathrm{~s})}^{0}$ is estimated to $\pm 0.3 \mathrm{~cm}^{3} \mathrm{~mol}^{-1} \mathrm{bar}^{-1},\left(1 \mathrm{bar}=10^{-5} \mathrm{~N} \mathrm{~m}^{-2}\right)$.

The data of Nakajama, Komatsu and Nakagawa ${ }^{3}$ are apparently the only literature values for $\phi_{k(s)}^{0}$ of alcohols in aqueous solution. The agreement is good where comparisons can be made.

The basis for calculating group molal compressibilities is the increment in isentropic molal compressibility per $\mathrm{CH}_{2}$ group. The mean value is $(-1.6 \pm 0.6) \times 10^{-4} \mathrm{~cm}^{3} \mathrm{~mol}^{-1} \mathrm{bar}^{-1}$ at $25{ }^{\circ} \mathrm{C}$. The standard deviation in the group molal compressibility of the $\mathrm{CH}_{2}$ group is larger than for the corresponding group partial molal volume from these homologous series. The additivity relation is thus less accurate for isentropic molal compressibilities than for partial molal volumes. However, in most cases addition of the isentropic group molal compressibilities given in Table 2 , results in values within the experimental error.

2-propanol has exceptionally large $\phi_{k(s)}^{0}$ values both at 25 and $35^{\circ} \mathrm{C}$. The same was observed for the partial molal volume. ${ }^{7}$ The

Table 2. Isentropic group molal compressibilities.

\begin{tabular}{|c|c|c|}
\hline & $\begin{array}{l}\phi_{\mathrm{k}(\mathrm{s})}^{0} \times 10^{4} \\
\mathrm{~cm}^{3} \mathrm{~mol}^{-1} \\
25^{\circ} \mathrm{C}\end{array}$ & $\begin{array}{l}\operatorname{bar}^{-1} \\
35{ }^{\circ} \mathrm{C}\end{array}$ \\
\hline $\begin{array}{l}\mathrm{CH}_{3}^{-} \\
\mathrm{CH}_{2}^{-} \\
\mathrm{CH}_{2} \mathrm{OH}^{-} \\
\mathrm{CHOH}\end{array}$ & $\begin{array}{r}0.8 \\
-1.6 \\
6.5 \\
2.2\end{array}$ & $\begin{array}{l}4.4 \\
0.8 \\
6.0 \\
0.7\end{array}$ \\
\hline
\end{tabular}

large partial molal volume was explained by a large empty volume due to the closeness of the two methyl groups. This explanation holds for the isentropic molal compressibility if large empty volumes lead to larger compressibilities.

Relations to van der Waals radii. Van der Waals radii for organic solutes can be computed from Bondi's data, ${ }^{10}$ and partial molal volumes can be calculated from eqn. (1). This has been done for some alkanes, alcohols, undissociated mono-, and di-carboxylic acids for which experimental data are accessible.,2,711 Reasonably good agreement between calculated and experimental data is obtained for the alkanes and higher alcohol homologues. However, when the solutes are of a more polar character, i.e. undissociated mono- and di-carboxylic acid, the agreement is poor as expected.

Eqn. (2) can now be used for calculating isentropic molal compressibilities. However, the value of $(\partial \Delta / \partial P)_{s}$ is not known and must be determined from the experimental data. If such a calculation is attempted, different values are obtained for each alcohol in each homologous series. This solvation model, a solute in a spherical cavity of radius $\left(r_{\mathrm{w}}+\Delta\right)$ is no longer capable of representing the experimental results. The reason seems obvious. When pressure is applied the hydration sheath is not uniformly compressed, as indeed is clearly demonstrated by the values of the group molal compressibilities.

The scaled particle theory. The intrinsic volume, $V_{\text {int }}$, eqn. (3), can be derived as follows: First $\bar{a}$ point particle is introduced in water. The volume increases due to its kinetic contribution to the pressure. This volume is then expanded against surface forces to make room for the solute of finite size. The reversible work done in this process can be calculated from the scaled particle theory. ${ }^{12}$ The expression reads as eqn. (7).

$\bar{V}_{\text {int }}=2.52 r^{3}+A^{\prime} r^{2}+A^{\prime \prime} r+A^{\prime \prime \prime}$

Values of the constants $A^{\prime}, A^{\prime \prime}$ and $A^{\prime \prime \prime}$ can be found in the literature for water as the solvent. ${ }^{6}$

The scaled particle theory was originally devised for calculating thermodynamic quan. tities of hard sphere or simple non-polar fluids, and the extension of the theory to aqueous solution may be questioned. However, it is 
still of considerable interest to use the theory for estimating intrinsic volumes. The most interesting quantity in this connection is $\Delta \bar{V}$, the volume change due to solute-solvent interactions. It is determined by the difference $\left(\bar{V}^{0}-\bar{V}_{\text {int }}\right)$. Values are given in Table $3 . \Delta \bar{V}$ is seen to be small for the alkanes, in fact zero for methane. It is decreasing in the order alkanes $>$ alcohols $>$ diols $\approx$ mono-carboxylic acids (undissociated) > di-carboxylic acids (undissociated). In each homologous series $\Delta \bar{V}$ is less negative the more methylene (non-polar) groups the solute contains.

The isentropic molal compressibility can in principle be calculated from eqn. (5); see eqn. (8).

Table 3. Values of $\Delta \bar{V}\left(=\bar{V}^{0}-\bar{V}_{\text {int }}\right)$ and $\Delta \phi(=$ $\left.\phi_{k(s)}^{0}-\phi_{\text {int }}\right)$ where the intrinsic volumes and compressibilities have been calculated from the scaled particle theory.

\begin{tabular}{|c|c|c|}
\hline & $\begin{array}{l}\Delta \bar{V} / \\
\mathrm{cm}^{3} \mathrm{~mol}^{-1}\end{array}$ & $\begin{array}{l}\Delta \phi \times 10^{4} / \\
\mathrm{cm}^{3} \mathrm{~mol}^{-1} \mathrm{bar}^{-1}\end{array}$ \\
\hline $\begin{array}{l}\text { Methane } a \\
\text { Ethane } \\
\text { Propane }\end{array}$ & $\begin{array}{r}0.0 \\
-1.7 \\
-2.8\end{array}$ & \\
\hline $\begin{array}{l}\text { 1-Propanol } \\
\text { 1-Butanol } \\
\text { 1-Pentanol } \\
\text { 1-Hexanol }\end{array}$ & $\begin{array}{l}-5.8 \\
-5.0 \\
-3.7 \\
-2.3\end{array}$ & $\begin{array}{l}-51 \\
-61 \\
-70 \\
-78\end{array}$ \\
\hline $\begin{array}{l}\text { 2-Propanol } \\
\text { 2-Butanol } \\
\text { 2-Pentanol } \\
\text { 2-Hexanol }\end{array}$ & $\begin{array}{l}-4.6 \\
-5.0 \\
-3.8 \\
-2.5\end{array}$ & $\begin{array}{l}-50 \\
-63 \\
-71 \\
-80\end{array}$ \\
\hline $\begin{array}{l}\text { 1,4-Butanediol } \\
\text { 1,5-Pentanediol } \\
\text { 1,7-Heptanediol } \\
\text { 1,2-Propanediol } \\
\text { 1,3-Butanediol } \\
\text { 2,3-Butanediol }\end{array}$ & $\begin{array}{r}-10.2 \\
-8.8 \\
-4.0 \\
-12.4 \\
-10.1 \\
-11.9\end{array}$ & $\begin{array}{l}-59 \\
-67 \\
-82 \\
-59 \\
-51 \\
-68\end{array}$ \\
\hline $\begin{array}{l}\text { Acetic acid }{ }^{c} \\
\text { Propionic } \\
\text { Butyric }\end{array}$ & $\begin{array}{r}-11.1 \\
-10.5 \\
-9.6\end{array}$ & $\begin{array}{l}-43 \\
-52 \\
-60\end{array}$ \\
\hline $\begin{array}{l}\text { Malonic acid } \\
\text { Succinic } \\
\text { Glutaric }\end{array}$ & $\begin{array}{l}-20.4 \\
-19.5 \\
-17.8\end{array}$ & \\
\hline $\begin{array}{l}\alpha \text {-Hydroxya.cetic }{ }^{d} \\
\alpha \text {-Hydroxypropionic } \\
\alpha \text {-Hydroxybutyric }\end{array}$ & $\begin{array}{l}-18.6 \\
-16.1 \\
-14.9\end{array}$ & $\begin{array}{l}-49 \\
-58 \\
-66\end{array}$ \\
\hline
\end{tabular}

${ }^{a}$ Ref. 11, $b$ Ref. 7, ${ }^{c}$ Ref. 4, ${ }^{d}$ Ref. 14.

$$
\begin{aligned}
& \left(\frac{\partial \bar{V}_{\text {int }}}{\partial P}\right)_{\mathrm{s}}=-\phi_{\text {int }}=\left(\frac{\partial A^{\prime}}{\partial P}\right)_{\mathrm{s}} r^{2}+\left(\frac{\partial A^{\prime \prime}}{\partial P}\right)_{\mathrm{s}} r+ \\
& \left(\frac{\partial A^{\prime \prime \prime}}{\partial P}\right)_{\mathrm{s}}
\end{aligned}
$$

The only additional data required in calculating $(\partial A / \partial P)_{\mathrm{s}}$ is $(\partial \beta / \partial P)$ where $\beta$ is the coefficient of compressibility. This was calculated from the data of Kell and Whalley ${ }^{13}$ assuming linearity between $(\partial \beta / \partial P)$ and $P$. The value is $-1.3 \times 10^{-8} \mathrm{bar}^{-2}$. Unfortunately, $(\partial A / \partial P)$ consist of two terms of opposing signs and of the same order of magnitude. The values of $(\partial A / \partial P)$ are thus very sensitive to any error in $(\partial \beta / \partial P)$. Numerically eqn. (6) reads as eqn. (9).

$10^{6} \times \phi_{\text {int }}=6.6 r^{2}+4.8 r+1.4$

$\phi_{\text {int }}$ calculated by eqn. (9) is positive for all the alcohols, and the values are larger than the experimental $\phi_{\mathrm{K}(\mathrm{s})}^{0}$ data by a factor of ten. This means that $\Delta \phi\left(=\phi_{\mathrm{K}(\mathrm{s})}-\phi_{\text {int }}\right)$ is correspondingly large and negative. Positive values of $\phi_{\text {int }}$ and negative $\Delta \phi$ values seem qualitatively correct. However, the extremely large values suggest that a solvation model based on calculating $\bar{V}_{\text {int }}$ and $\phi_{\text {int }}$ from the scaled particle theory fails for the compres. sibilities. Since this solvation model is basically the same as the van der Waals model outlined above, this is not surprising.

In conclusion these results show that molal compressibilities are more sensitive to deficien. cies in proposed solvation models than the partial molal volumes. The reason for this, as mentioned above, must be that the hydration sheath is not uniformly compressed when pressure is applied. If the group molal compressibilities are inspected, Table 2, it is revealed that the hydration sheath around hydrophilic groups are more easily compressed than the sheath around hydrophobic groups, and that end groups have higher groups molal compressibilities than the other groups of the solute molecule.

\section{REFERENCES}

1. Traube, J. Samml. Chem. Vortr. 4 (1899) 255.

2. Høiland, H. Acta Chem. Scand. A 28 (1974) 699.

3. Nakajima, T., Komatsu, T. and Nakagawa, T. Bull. Chem. Soc. Jpn. 48 (1974) 788 .

Acta Chem. Scand. A 30 (1976) No. 9 
4. Høiland, H. and Vikingstad, E. J. Chem. Soc. Faraday Trans. 1, 72 (1976) 1941.

5. Edward, J. T. and Farrell, P. G. Can. J. Chem. 53 (1975) 2965.

6. Hirata, F. and Arakawa, K. Bull. Chem. Soc. Jpn. 46 (1973) 3367.

7. Høiland, H. and Vikingstad, E. Acta Chem. Scand. A 30 (1976) 182.

8. Garnsey, R., Mahoney, R. and Litovitz, T. A. J. Chem. Phys. 64 (1964) 2073.

9. Del Grosso, V. A. and Mader, C. W. $J$. Acoust. Soc. 52 (1972) 1442.

10. Bondi, A. J. Phys. Chem. 68 (1964) 441.

11. Masterton, W. L. J. Chem. Phys. 22 (1954) 1830.

12. Pierotti, R. A. J. Phys. Chem. 67 (1963) 1840.

13. Kell, G. S. and Whalley, E. J. Chem. Eng. Data 12 (1967) 67.

14. Høiland, H. and Vikingstad, E. J. Chem. Soc. Faraday Trans. 1, 71 (1975) 2007.

Received March 22, 1976. 